\title{
Validation of SWAT model for stream flow simulation and forecasting in Upper Bernam humid tropical river basin, Malaysia.
}

\begin{abstract}
The study was to evaluate SWAT model for flow simulation and forecasting in the Upper Bernam humid tropical river basin, which is the main source of irrigation water supply for a rice granary. Land use in the study area has rapidly changed from the year of 1984 until today. The study was conducted using 27 years of records (1981-2007). Calibration was performed for the period of 1981 through 2004 while, the period of 2005 through 2007 for the validation of both simulation and forecasting of flow. During calibration, the annual and monthly results were $0.82,0.65,0.81$ and 0.62 for R2 and ENS, respectively and 0.99, 0.93, 0.98 and 0.92 , respectively during validation. As for forecasting validation, were $0.88,0.78$, 0.86 and 0.74 for R2 and ENS, respectively. In general model shows good performance in flow simulating as well as forecasting. Five scenarios were performed to identify the individual effect of mixed land use change on stream flow. The scenarios results demonstrate, land use changes are responsible for an increase in the annual flow depth between $8 \%$ to $39 \%$ while $16 \%$ to $59 \%$ during high flow months and decreases between $3 \%$ to $32 \%$ during low flow months. Flow forecasting for the year 2020 using 30 forecasting cycles which found to be the optimal for the study area was performed. The results show decrease by $50 \%$ below the monthly irrigation water demand during low flow months, which emphasize the need to include structured best management practices (BMPs) such as ponds to the study area future land development plan to mitigate the future changes in land use on flow quantity. This study showed that SWAT was able to simulate and forecast flow in humid tropical condition successfully and can be used to study the effects of future land use changes on flow.
\end{abstract}

Keyword: SWAT; Upper Bernam; Tropical river basin; Forecast flow. 